\title{
Relationship of daytime asthma symptom frequency to morning peak expiratory flow
}

\author{
H.A. Atherton, P.T. White, G. Hewett, K. Howells
}

Relationship of daytime asthma symptom frequency to morning peak expiratory flow. H.A. Atherton, P.T. White, G. Hewett, K. Howells. CERS Journals Ltd 1996.

ABSTRACT: Since management plans based on peak flow measurements are increasingly used, the relationship between peak flow rate and ensuing symptom frequency is of particular interest to the treatment of asthma. The objective of this study was to examine to what extent morning peak flow was related to symptom frequency during the day.

In 168 out of 307 randomly selected adult asthmatics from a general practice population, adequate recordings of morning peak flow (amPF) and symptom frequency during the day (DSF) were obtained for 28 days. In each individual, the relationship between these two variables was studied and the mean values of these two variables over 28 days were calculated. The relationship between the means of the variables was also examined for the group as a whole.

In individuals, the correlation between amPF and DSF varied widely; only $16 \%$ of patients had a good relationship (Pearson $r=-1$ to $\mathbf{- 0 . 5}$ ). For the whole group, the relationship between mean amPF and mean DSF best fitted a curvilinear model $(r=-0.6)$. This was unaffected by age, sex or the use of inhaled steroids.

For the majority of asthmatics, morning peak flow may be an unreliable predictor of expected symptoms during that day. Reliance on peak flow measurement as a tool enabling asthmatics to manage their asthma on a daily basis needs to be reconsidered.

Eur Respir J., 1996, 9, 232-236.
Dept of General Practice and Primary Care, King's College School of Medicine and Dentistry, London, UK.

Correspondence: H.A. Atherton

Dept of General Practice and Primary Care King's College School of Medicine and Dentistry

Bessemer Rd

London SE5 9PG

Keywords: Asthma

lung function

symptom perception.

Received: January 231995

Accepted after revision October 311995
Peak flow recording is an important tool in the management of asthma patients. Several authors support the use of self-management regimens based on peak flow measurement [1-3], and prescription and use of peak flow meters is now recommended in the latest British Thoracic Society (BTS) guidelines for the treatment of asthma [4]. Certainly, peak flow meters have potential for improving both the patient's and the doctor's management of asthma, especially in those patients with severe asthma [5]. The assumption is that patients will adjust their medication for optimal control in response to peak flow readings. However, this type of behaviour requires a disciplined attitude on the part of the patient and may not be suitable for the majority of patients in a general practice setting. In a small carefully monitored study, BeAsLey et al. [1] have shown that when a therapeutic management plan based on morning peak flow measurements was followed for 6 months, asthma symptoms and lung function improved. In contrast however, Charlton et al. [2] showed no difference between a peak flow and symptoms only management plan in general practice.

In reality, patients are probably less organized about recording peak flow than clinicians would wish, and rely on symptoms to direct their daily use of drugs. A poor relationship between morning peak flow and ensuing symptoms may not encourage the use of appropriate prophylactic medicine on a long-term basis and may undermine peak flow meter use.

The relationship between the perception of symptoms and lung function for asthmatics is poorly understood. Most studies of the perception of symptom severity and its relation to lung function have been carried out using bronchial provocation [6-8]. In these closely monitored conditions, only a moderate correlation between the perception of breathlessness and lung function has been shown. In general practice, Horn and Cochrane [9] reported, on the basis of a single interview, a poor correlation (Pearson $\mathrm{r}=-0.22$ ) between the patients' assessment of breathlessness severity over the preceding year on a visual analogue scale and forced expiratory volume in one second (FEV1). JONES et al. [10], on the other hand, found a significant association between mean peak flow rate (PFR) and a three point morbidity index in general practice. Kendrick et al. [11] and PEIFFER et al. [12] divided patients in general practice into poor and good discriminators, on the basis of the correlation between their individual peak flow rate to severity of asthma. Other authors support the idea that some patients are less able to sense bronchoconstriction through symptom perception than others $[6,7]$. In order to promote the use of peak flow meters in general practice with confidence, 
our understanding of the relationship of peak flow with symptoms must improve.

This paper reports an investigation of the relationship between morning peak flow measurements and the frequency of reported asthma symptoms during the day in a general practice setting. A deeper understanding of this relationship is increasingly important as peak flow recording becomes more widely used in asthma self-management plans and consultation.

\section{Methods}

\section{Study design}

The data were reported by patients aged 14-66 yrs from 23 inner city practices in the Lambeth Southwark and Lewisham Health Authority. Three hundred and seven patients were randomly selected from 1,296 patients notified by general practitioners (GPs) as having a diagnosis of asthma and receiving asthma specific remedies. All 307 patients were asked to complete a 4 week peak flow and symptom diary, and were offered oral and written instructions about how to fill in the diaries and use peak flow meters (mini-Wright, Airmed). Each diary covered a 4 week period and asked patients to record their PFR, and their symptoms of breathlessness, wheeze and cough. Patients were asked to record the best of three peak flow readings in the morning and in the evening before taking any medication. Specific instructions were also given not to record peak flows retrospectively. Patients were not asked to record drug use. In the evening, they were also asked to score the frequency of each symptom which they had experienced during that day as one of four categories (not at all, once only, twice or more, or all day). Diaries were judged usable if at least 14 days had been fully completed.

\section{Analysis of the data}

The relationship between morning peak flow and daily symptom frequency was examined both for individuals and for the group of patients as a whole. Although the data for the evening peak flow was also obtained, its analysis has not been included in this paper because it was less closely related to symptoms than morning peak flow, and its use as an indicator for daily symptoms was less likely to be employed by patients.

Individual respondents. The morning peak flow for each completed day of the diary was expressed as a percentage of the expected peak flow (amPF\%) using the formulae from NunN and GREgG [13]. These values were then used to calculate a mean morning percentage peak flow ( $\bar{x}$ amPF\%) for each individual. A value was allotted to the frequency category for all three symptoms recorded at the end of the day (not at all $=0$; once only $=1$; twice or more $=2$; or all day $=3$ ). For the purposes of analysis, a continuous variable, the daily symptom frequency (DSF) score was devised by summing these values for each day (maximum possible $\mathrm{DSF}=9$ ). A mean symptom frequency score ( $\overline{\mathrm{x}} \mathrm{DSF})$ for each patient was calculated.

The data was considered in two ways: 1) amPF\% was plotted with the daily symptom frequency score DSF on a double y-axis for each day of the diary. This visual method of examining the data allowed us to observe the different ways in which morning peak flow might be related to symptoms during the day. 2) Linear regression analyses were carried out between the amPF\% and DSF. A correlation coefficient was obtained for each respondent.

All respondents. Multiple regression analysis was performed between the mean morning peak flow ( $\bar{x}$ amPF\%) and mean symptom frequency ( $\mathrm{x} D S F)$ to determine the equations which gave the best fit with the data. Age, sex and the use of inhaled steroids were subsequently introduced as covariants. Using the descriptive equation for the relationship, the standardized residual for each patient was calculated, and a comparison was made between the ages, sex, and use of inhaled steroids for those patients whose residual was greater than 1 SD (outliers), and those whose residual was less than 1 SD (non-outliers).

\section{Results}

\section{Patient profile}

Three hundred and seven patients (58\% female; mean age 36 (SD 15) yrs) were asked by letter to complete diaries. Two hundred and thirty one patients agreed and 150 of these accepted oral instruction. One hundred and ninety nine diaries were returned $(69 \%$ had received oral instruction) of which 185 (60\%) were usable. The variation both morning and evening peak flow over the diary period (difference between maximum and minimum reported peak flow expressed as a percentage of maximum) was greater than $15 \%$ in $168(55 \%)$ patients. These were judged to have active asthma during the study period and used in the final analysis. The mean number of days completed in the diaries was $26 \%$. $45 \%$ of male respondents and $49 \%$ of female respondents were using inhaled steroids. Table 1 presents the characteristics of the final 168 patients. In our sample, female patients were more numerous, with a significantly lower mean morning peak flow value than males. There were no significant differences between males and females in their ages or in the number of days on which symptoms were recorded.

Table 1. - Characteristics of 168 patients who returned usable diaries of peak flow and symptoms

\begin{tabular}{lccc}
\hline & All & Female & Male \\
\hline $\mathrm{n}$ & 168 & 102 & 66 \\
Age yrs & $40 \pm 13$ & $38 \pm 13^{\$}$ & $41 \pm 14$ \\
& $(15-65)$ & $(15-62)$ & $(16-65)$ \\
xamPF\% & $61 \pm 20$ & $56 \pm 16^{*}$ & $70 \pm 23$ \\
& $(14-112)$ & $(14-86)$ & $(23-112)$ \\
Days with & $63 \pm 34$ & $67 \pm 32^{\$}$ & $58 \pm 37$ \\
symptoms \% & $(0-100)$ & $(0-100)$ & $(0-100)$ \\
\hline
\end{tabular}

*: Student's t-test; $\mathrm{t}=4.30, \mathrm{df}=102, \mathrm{p}=0.0001 ; \$$ : Student's t-test, nonsignificant. 
Morning peak flow recording and daily symptom recording for the whole diary

The amPF\% and DSF were plotted on a double y-axis for all the days of the diary for all patients. Figure 1 presents examples of the varied daily patterns of symptom and peak flow recording. Figure $1 \mathrm{a}$ and $\mathrm{b}$ contrast such plots for two male patients (Nos. 1 and 2) of similar age and height who completed a full 28 days of the diary. Figure 1a presents patient No. 1 who consistently recorded near normal peak flows along with frequent reporting of symptoms. Figure 1b) presents patient No. 2 with peak flow reduced to below $70 \%$ of expected on all days, who on most days showed no symptoms but during a group of days when peak flow was below $50 \%$ was always symptomatic. The Pearson correlation coefficients for the relationship between amPF\% and DSF

a)

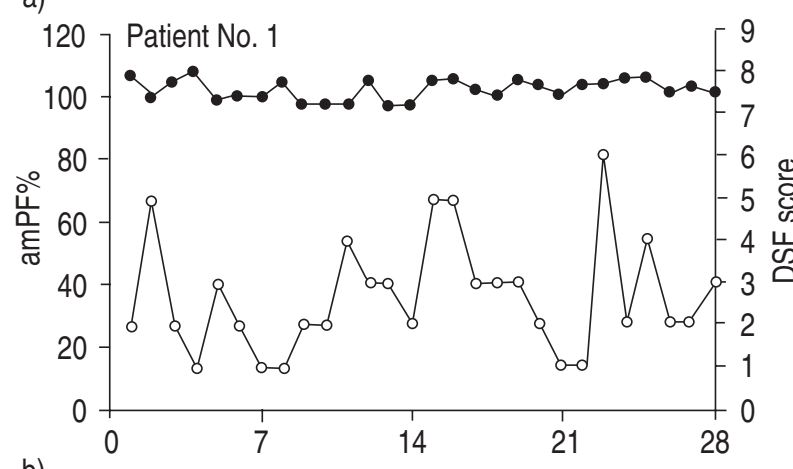

b)
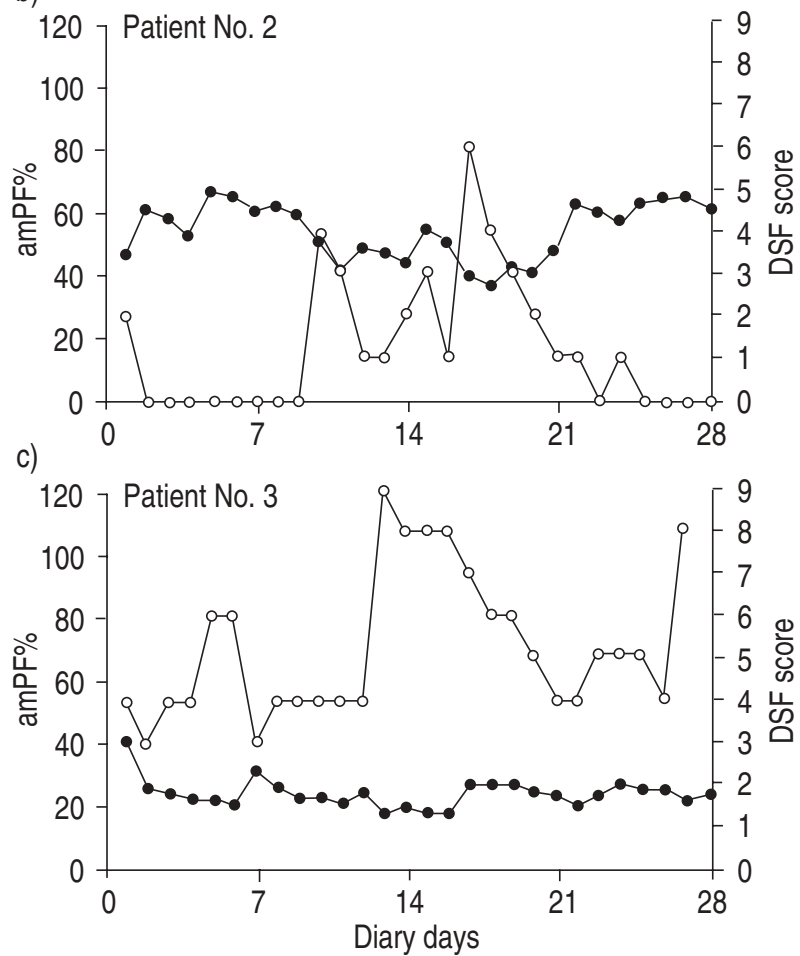

Fig. 1. - The recorded morning peak flow rate and symptom frequency reported in the evening plotted over 28 days for three patients showing different relationships between the two variables. amPF\%: morning peak flow rate expressed as percentage of expected peak flow; DSF: daily symptom frequency. $\rightarrow-$ : amPF\%; $\multimap-$ : DSF score. were $\mathrm{r}=0.001$ for patient No. 1 and $\mathrm{r}=-0.800$ for patient No. 2. Figure 1c presents the same type of plot for patient No. 3 who is less consistent than patient No. 2 in symptom reporting. The peak flow is routinely below $30 \%$ of expected and the patient is always symptomatic though not extensively so. Only when the amPF\% falls to $22 \%$ of expected does the patient exhibit extensive symptoms. The correlation coefficient for this patient was $r=0.51$.

Relationship between morning peak flow and daily symptom frequency for individual patients

The relationship between the morning peak flow reading and symptoms arising during the ensuing day was highly variable. The mean correlation coefficient (r-value) was -0.13 (SD 0.40) and there was a significant difference $(\mathrm{t}=2.51, \mathrm{p}<0.014)$ between this value for males $(\mathrm{r}=$ -0.027 , sD 0.453$)$ and females ( $\mathrm{r}=-0.192$, sD 0.341$)$. Only $16 \%$ of the individual correlation coefficients were between -1.00 and -0.50 , representing patients for whom a good inverse relationship between amPF\% and DSF existed over the month in question (see patient No. 1, fig. 1). A further $21 \%$ had r-values between -0.50 and -0.25 , a group of patients for whom the relationship was less close. Sixty three percent of the patients showed a poor relationship between DSF and amPF\% or a relationship in which symptoms increased as peak flow rose $(r=-0.25$ to 1.00). An $r$ value of 1.00 was seen in six patients who reported no symptoms at all throughout the whole of the diary. There was no correlation in the group as a whole between the r-values for each patient and their individual ranges of peak flow (Pearson $r=-0.02$ ). The $r$-value was only moderately related to the number of days on which symptoms were reported $(\mathrm{r}=-0.30)$.

Relationship between mean morning peak flow and mean daily symptom frequency for the group of patients

The $\bar{x}$ DSF was plotted against the $\bar{x}$ amPF\% for the whole group of 168 patients (fig. 2). Using multiple regression analysis, the relationship between the two could best be described by the equation:

$$
y=(21.4+0.055 x)-(12.9 / \log (x))
$$

where $\mathrm{y}=\overline{\mathrm{x} D S F}$ and $\mathrm{x}=\overline{\mathrm{x}} \mathrm{amPF} \%$. The curvilinear line of best fit from this relationship is shown in figure 2 . The correlation coefficient for the group was $r=-0.6$. The relationship was not significantly affected by the age of the patient or use or otherwise of inhaled steroids. When sex was incorporated as a covariant, the significance of the effect was $\mathrm{p}=<0.07$. (males $\mathrm{r}=-0.674$; females $\mathrm{r}=-0.581$ ). Examination of the data for either sex revealed different patterns in symptom recording and peak flow reading. The proportion of males with $\mathrm{x}$ amPF\% greater than $90 \%$ of expected was $23 \%$ (females $0 \%$ ) and with a $\bar{x}$ amPF\% less than $40 \%$ expected was $9 \%$ (females $17 \%$ ). However, both sexes had similar proportions reporting $\bar{x}$ DSF over a value of 3 : females $20 \%$ and males $23 \%$. 


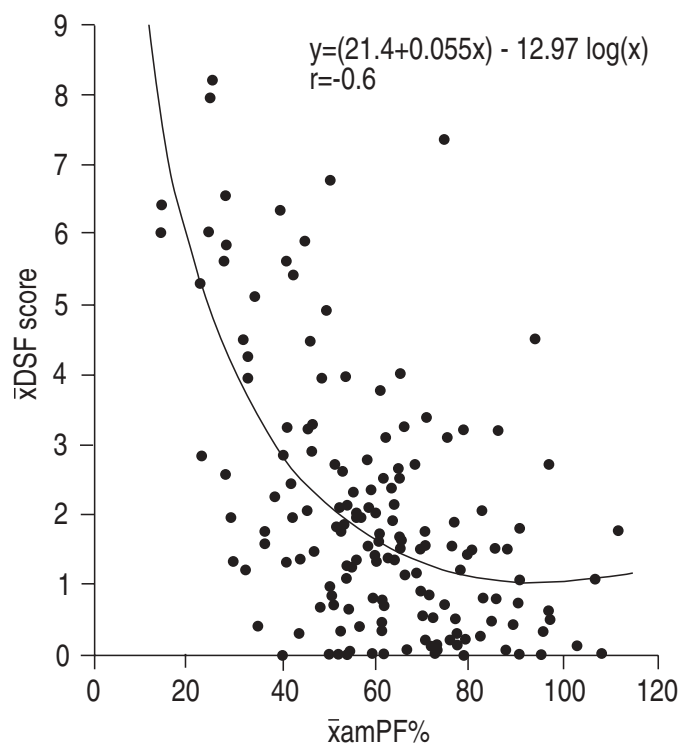

Fig. 2. - The relationship between mean morning peak flow ( $\bar{x} a m P F \%)$ and mean symptom frequency ( $\mathrm{x} D S F)$ score during the day for 168 patients with asthma. The line of best fit is shown and described by the equation.

The mean age of outliers $(n=44)$ was $44(\mathrm{SD} \pm 13$ yrs) and of non-outliers $(\mathrm{n}=124)$ was $38(\mathrm{SD} \pm 13 \mathrm{yrs})$ (Student's t-test: $\mathrm{t}=2.92 ; \mathrm{p}=<0.005)$. The outliers were equally divided between the sexes, although $34 \%$ of males were outliers and $21 \%$ of females were outliers (Chi-squared 3.21; $\mathrm{p}<0.07)$. There was no association between use of inhaled steroids and being included in the outlier category.

\section{Discussion}

We have shown that in a group of asthmatics in primary care the relationship between the mean morning peak flow rate and the frequency of asthma symptoms experienced during the ensuing day was only moderate. Examination of this relationship for individuals suggests that only a small proportion of patients might equate a low morning peak flow rate with a symptomatic day. This has obvious implications for the use of peak flow meters in the management of asthma in general practice.

General concerns have been expressed about the reliability of home peak flow monitoring, both from the point of view of the accuracy of the meter itself [14], and the ability of the patient to use the meter correctly and consistently [15]. These issues have important implications for clinical practice. In this study, errors arising from inaccurate and inconsistent use are likely to be randomly distributed throughout the study subjects. In addition, the method of the study was intended to minimize the intrusion made by the device and the diary so that the recording of peak flow and symptoms would mimic as closely as possible their use in normal clinical practice.

As a group, the study patients showed a wide variation in the frequency of asthma symptoms and the number of days on which symptoms were recorded. The range of peak flow values was also widely distributed. It thus seems likely that these patients represented moderately severe asthmatic patients from general practice. Approximately half were using inhaled steroids. However, differing patterns of symptom and peak flow reporting were discernible for subgroups. Women, for example, reported lower morning peak flows than men but their symptom reporting was similar. A closer consideration of each person's morning peak flow rate and symptoms over the 28 days of the diary highlighted the different patterns in individuals. Some reported frequent symptoms at near normal peak flows and yet others did not report symptoms at low peak flows. Such differences are probably due not only to psychological factors which affect the reporting and perception of symptoms but also to differing physiological mechanisms of symptom perception.

Our investigation of the relationship between symptom frequency and peak flow rate differs from other studies. In the first place, it examines symptom frequency rather than severity; secondly, breathlessness, wheeze and cough are taken into account and thirdly, morning peak flow recording is assessed as a predictor for ensuing symptoms. Many of the studies carried out so far have used breathlessness as the sole criterion for assessing symptoms of asthma $[6,16]$. This may not reflect the true picture of asthma symptoms in primary care. Recording the three cardinal daytime asthma symptoms would, for example, take into account the symptomatology of a patient who coughed but did not feel breathless. Daily symptom frequency is only one of several alternative ways, including visual analogue scales [11], symptom severity and morbidity indices $[9,10]$, to assess the severity of asthma.

Symptom frequency provides a more objective measure of the patient's asthma than does symptom severity, and yet the two are intimately related. It is only when a patient's symptoms are severe enough to be perceived that their occurrence will be reported; but the threshold of perception is different for all patients and will be influenced by external factors. Recording symptoms at a distance from peak flow allows other factors, such as drug use, daily events, smoking and exposure to allergens, to affect the relationship. The perception of asthma and the decision to use treatment may be influenced as much by such factors as it is by morning peak flow.

Our results are in broad agreement with other studies of the relationship between lung function and symptoms: that the correlation is moderate in the group as a whole and varies widely between patients. RUBINFELD and PAIN [6] investigated the perception of asthma severity after methacholine-induced bronchoconstriction and found that $15 \%$ of patients (whom they termed "poor perceivers") were unable to sense severe bronchoconstriction. In a study in primary care measuring asthma severity on a visual analogue scale, KENDRICK et al. [11] reported that $60 \%$ of patients were unable to discriminate a low peak flow. FRITZ et al. [17] investigated the relationship between peak flow and severity of asthma in adolescents; $22 \%$ of their patients had correlation coefficients of between -1 and -0.6 , a not dissimilar proportion to the $16 \%$ between -1 and -0.5 which we report. The exact proportions of those whose relationship between peak flow and symptoms is good will vary according to the patient sample and the method of measuring the asthma. 
Previous authors $[6,7,12]$ have described the relationship between peak flow and symptoms in a group of patients in terms of linear regression. However, a curvilinear regression in which symptoms increase only slowly as peak flow decreases until a threshold is reached may fit the clinical experience better than a simple linear regression. Many patients in this study do not report extensive symptoms until the peak flow falls below a particular threshold. This is probably individual for each patient but has a mean of about $40 \%$ expected peak flow rate for this sample. At extremely low peak flows a patient might be too distressed to record peak flows or symptoms. Peak flow may never fall below the threshold value in some asthmatics, either because they manage their asthma well or because they avoid situations or activities in which peak flow may be reduced. In such patients, the variation of peak flow above their individual threshold may be substantial. However, a relationship between symptoms and peak flow may not be apparent until peak flow falls below the threshold.

Many self-management plans for asthma in general practice presume that patients will accept the idea that a reduced peak flow means that their asthma symptoms will occur or worsen. However, this study suggests that measuring peak flow in the morning would enable only $16 \%$ of patients to reliably predict symptoms. Conversely, only $16 \%$ of patients would associate a reduced morning peak flow with the likelihood of their symptoms occurring during the day. Morning peak flow readings would have minor predictive value for $21 \%$ of patients and none at all for $63 \%$, and thus prophylactic treatment based on such readings may be construed by the patient as irrelevant. It is important to be alert to the relationship between peak flow and asthma symptoms but not to forsake either when managing individual patients.

This study has highlighted some aspects of the relationship between symptom reporting and peak flow measurement, which may be important for asthma management, especially in general practice. A curvilinear relationship for the patients as a group emphasizes the fact that symptoms may only become significantly frequent after a threshold is reached. However, the pattern of the group may not forecast that of the individual. Among the asthmatics in this study, the mean morning peak flow was only moderately related to subsequent reporting of symptoms during the day. Thus, while one patient who reports few symptoms in the consultation may have a near normal peak flow others in whom the symptom threshold is low may actually have low peak flow and absence of symptoms. This study suggests that many patients are unlikely to find a self-management plan using peak flow readings useful because their individual experience tells them that symptoms and peak flow rate are poorly related.

We conclude that: 1) the relationship between mean morning peak flow and mean symptom frequency during that day in a sample of asthmatics in primary care seems best described by a curvilinear model. 2) The relationship of morning peak flow to symptom frequency in the same day varies widely between asthma patients. This relationship was only good $(\mathrm{r}=-1.0$ to -0.5$)$ in $16 \%$ of patients. 3) The use of peak flow meters to assist patients in the management of their asthma on a daily basis needs to be re-examined. For optimum management it may be necessary to define this relationship for each patient.

\section{References}

1. Beasley R, Cushley M, Holgate ST. A self-management plan in the treatment of adult asthma. Thorax 1989; 44(3): 200-204.

2. Charlton I, Charlton G, Broomfield J, Mullee M. Evaluation of peak flow and symptoms only self-management plans for the control of asthma in general practice. Br Med J 1990; 301 1355-1359.

3. Gregg I. Can measurement of peak expiratory flow enhance compliance in chronic asthma? Eur Respir $J$ 1992; 5(1): 136-138.

4. Guidelines on the Management of Asthma. Statement by the British Thoracic Society, the British Paediatric Association, the Research Unit of the Royal College of Physicians of London, the King's Fund Centre, the National Asthma Campaign, the Royal College of General Practitioners, the General Practitioners in Asthma Group, the British Association of Accident and Emergency Medicine, and the British Paediatric Respiratory Group. Thorax 1993; 48:(Suppl. 2): S1-2.

5. Drummond N, Abdalla M, Beattie AG, et al. Effectiveness of routine self monitoring of peak flow in patients with asthma. Br Med J 1994; 308: 564-567.

6. Rubinfeld AR, Pain MCF. Perception of asthma. Lancet 1976; i: 882-884.

7. Burdon JG, Juniper EF, Killian KJ, Hargreave FE, Campbell EJ. The perception of breathlessness in asthma. Am Rev Respir Dis 1982; 126(5): 825-828.

8. Janson C, Herala M. Dyspnea in acute asthma: relationship with other clinical and physiologic variables. Ann Allergy 1993; 70(5): 400-404.

9. Horn CR, Cochrane GM. An audit of morbidity associated with chronic asthma in general practice. Respir Med 1989; 83(1): 71-75.

10. Jones KP, Bain DJ, Middleton M, Mullee MA. Correlates of asthma morbidity in primary care. Br Med J 1992; 304(6823): 361-364.

11. Kendrick AH, Higgs CMB, Whitfield MJ, Laszlo G. Accuracy of perception of severity of asthma: patients treated in general practice. Br Med J 1993; 307: 422-424.

12. Peiffer C, Marsac J, Lockhart A. Chronobiological study of the relationship between dyspnoea and airway obstruction in symptomatic asthmatic subjects. Clin Sci 1989; 77(3): 237-244.

13. Nunn AJ, Gregg I. New regression equations for predicting peak expiratory flow in adults. $\mathrm{Br} M e d J 1989$; 298: 1068-1070.

14. Miller M, Quanjer P. Peak flow meters: a problem of scale. Br Med J 1994; 308: 548-549.

15. Hyland ME, Kenyon CAP, Allen R, Howarth P. Diary keeping in asthma: comparison of written and electronic methods. Br Med J 1993; 306: 487-489.

16. Turcotte H, Corbeil F, Boulet C. Perception of breathlessness during bronchoconstriction induced by antigen, exercise and histamine challenges. Thorax 1990; 45: 914-918.

17. Fritz GK, Klein RB, Overholser JC. Accuracy of symptom perception in childhood asthma. J Dev Behav Paediatr 1990; 11: 69-72. 